ORIGINAL ARTICLE

\title{
Coverage of work related fatalities in Australia by compensation and occupational health and safety agencies
}

\author{
T Driscoll, R Mitchell, J Mandryk, S Healey, L Hendrie, B Hull
}

Occup Environ Med 2003;60:195-200

See end of article for authors' affiliations

Correspondence to: Dr T R Driscoll, Elmatom Pty Ltd, 49 Taleeban Road,

Riverview, NSW 2066

Australia;

elmatom@optushome.com.au

Accepted 20 June 2002
Aims: To determine the levels of coverage of work related traumatic deaths by official occupational health and safety (OHS) and compensation agencies in Australia, to allow better understanding and interpretation of officially available statistics.

Methods: The analysis was part of a much larger study of all work related fatalities that occurred in Australia during the four year period 1989 to 1992 inclusive and which was based on information from coroners' files. For the current study, State, Territory, and Commonwealth OHS and compensation agencies were asked to supply unit record information for all deaths identified by the jurisdictions as being due to non-suicide traumatic causes and which were identified by them as being work related, using whatever definitions the agencies were using at the relevant time. This information was matched to cases identified during the main study.

Results: The percentage of working deaths not covered by any agency was 34\%. Only 35\% of working deaths were covered by an OHS agency, while $57 \%$ were covered by a compensation agency. The OHS agencies had minimal coverage of work related deaths that occurred on the road (to workers $(8 \%)$ or commuters $(3 \%))$, whereas the compensation system covered these deaths better than those of workers in incidents that occurred in a workplace (65\% versus $53 \%$ ). There was virtually no coverage of bystanders (less than $8 \%$ ) by either type of agency. There was marked variation in the level of coverage depending on the industry, occupation, and employment status of the workers, and the type of injury event involved in the incident.

Conclusions: When using data from official sources, the significant limitations in coverage identified in this paper need to be taken into account. Future surveillance, arising from a computerised National Coroners Information System, should result in improved coverage of work related traumatic deaths in Australia.
$\mathrm{O}$ fficial State, Territory, and Commonwealth occupational health and safety (OHS) and workers' compensation ("compensation") agencies are the main sources of statistics on OHS in Australia. In Australia and many western countries, most government funded prevention activities are based on information from these agencies. Many other individuals and groups in the OHS community, such as insurance institutions, researchers, educators, employers, and unions, also rely on this information to inform their activities. If prevention activity is to be appropriately planned and evaluated, it is important that the overall coverage, and the coverage of particular subgroups of workers or incident types, by these agencies is known. However, the completeness of coverage by these agencies of traumatic fatalities relating to work is not well known. In Australia, there is no reliable infor-

\section{Main messages}

- Public OHS and compensation agencies have deliberate and practical limitations on their coverage of work related fatal incidents.

- Official data from OHS and compensation agencies significantly underestimate the extent of work related traumatic death in the community.

- The extent of underestimation of work related fatalities varies considerably depending on the circumstances of the fatality.

- Coroners' records potentially provide excellent coverage of work related fatalities. mation on this. Information from other countries, largely based on comparing data from multiple but incomplete data sources, suggests that official statistics on work related traumatic death provide a significant underestimate of the true number of work related traumatic deaths. ${ }^{1-7}$ The situation is as bad, or worse, for non-fatal injuries. ${ }^{8-11}$

A recently completed investigation of work related fatalities in Australia, based on coroners' records, ${ }^{12}$ provided an opportunity to accurately determine the coverage of such deaths by the OHS and compensation agencies. Since coroners investigate all external cause deaths in Australia, the data obtained from coroners' records should, in theory, have included all work related fatalities that occurred in Australia during the study period. The data could, therefore, be used as a "gold standard" against which agency data could be measured. Unfortunately, coroners' records currently are poorly accessible and do not always contain details useful for

\section{Policy implications}

- Surveillance of work related fatalities should not be based only on information from official OHS and compensation agencies.

- Priority setting regarding work related fatality prevention should not be based only on information from official OHS and compensation agencies.

- OHS agencies should be encouraged to investigate and report on ALL traumatic deaths related to work activities. 
prevention. Therefore, other data sources such as OHS and compensation agencies are commonly used.

The purposes of the analysis described here were to determine overall levels of coverage of work related traumatic deaths by official OHS and compensation agencies, and identify which occupations, industries, and incident types are well covered, and which areas are less well covered, by official agency data sources.

\section{METHODS}

The analysis presented here was part of a much larger study of all non-suicide work related traumatic deaths that occurred in Australia during the four year period 1989 to 1992 inclusive, and that was based on information collected from coroners' files in each of the Australian States and Territories. The coroners' files relating to these deaths were read, and deaths classified as cases (work related), non-cases (not work related), or indeterminate. The methodology used in the larger study is described in detail elsewhere. ${ }^{12}$

A broad definition of work relatedness was used in this study, and cases were divided into eight categories. Of particular interest for this analysis were the "working" (including self employed), "commuting" (travelling to or from the place of work), and "bystander" (not working but fatally injured as a result of work activities) categories. The other categories were volunteer, student, home duties, and other on-farm.

The working group was the main group of interest and the focus of the data presented in this paper. The working group was divided into two subgroups: "workplace" and "workroad". The work-road group comprised workers who were killed in motor vehicle crashes on public roads in the course of their work (note that this group did not include commuters). The workplace group comprised all other workers who were fatally injured as a result of work activity. These people were usually injured in some form of fixed workplace (such as a factory, construction site, or farm).

\section{OHS and compensation agency information \\ Requested data}

The State, Territory, and Commonwealth OHS and compensation agencies were asked to supply unit record information for all deaths identified by the jurisdictions as being due to nonsuicide traumatic causes and which were identified by them as being work related, using whatever definitions the agencies were using at the relevant time. (Some other agencies that covered specific sectors of the workforce were also approached, but none supplied data.) For most jurisdictions this encompassed two lists-one for deaths covered by the OHS agency or division and another for the compensation agency or division. It was expected that many of the names would be common to both lists, but that some names would appear on only one of the lists.

The relevant agencies in each jurisdiction were asked for a list of:

- All non-suicide external cause deaths that occurred on or between 1 January 1989 and 31 December 1992, rather than claims, notifications, or incidents that occurred during this time period

- All (and only) deaths that the relevant agency or division deemed work related (if an OHS agency or division) or compensable (if a compensation agency or division), including deaths related to motor vehicle crashes and commuting deaths

- Separate lists for deaths relevant to the OHS division and the compensation division if OHS and compensation matters were covered by the same agency

- Any relevant information, such as industry, occupation, age, and date of incident, that might aid in the matching process.
Table 1 Outcome of matching OHS and compensation agency information with information obtained from coroners, by jurisdiction; Australia, 1989 to $1992 *$

\begin{tabular}{lrr}
\hline Outcome & $\begin{array}{c}\text { Compensation }^{\text {agencies }^{1}} \\
\text { Case }\end{array}$ & OHS agencies \\
\hline In jurisdiction of incident & \\
In other jurisdiction & 1216 & 539 \\
$\quad$ Total cases & 68 & 0 \\
& 1284 & 539 \\
Not a case & & \\
$\quad$ Did not meet study definitions & 52 & 38 \\
Natural cause & 752 & 32 \\
Suicide & 29 & 3 \\
Did not die & 17 & 0 \\
$\quad$ Not in study period & 95 & 2 \\
Incident occurred overseas & 2 & 0 \\
$\quad$ Repeat in same jurisdiction & 32 & 0 \\
Rejected later by jurisdiction & 59 & 0 \\
Missing & 16 & 0 \\
Total on supplied agency list & 2338 & 614 \\
\hline
\end{tabular}

*Excluding the Australian Capital Territory and Western Australia. This table only includes persons recorded on one or more of the lists supplied by the agencies.

1: The Northern Territory and Tasmania provided single compensation and OHS lists, both of which are considered in this column and not the OHS agency column.

2: Persons included as work related cases in the overall work related fatalities study. ${ }^{12}$

3: There were 10 duplications between jurisdictions (including five with Comcare). These have been allocated to the jurisdiction in which the incident occurred.

4: Persons not included as work related cases in the overall work related fatalities study ${ }^{12}$ and reasons for exclusion.

5: Unable to match name on agency list with a name in the overall work related fatalities study and no other known reason for exclusion. ${ }^{12}$

\section{Data received}

Of the eight States and Territories and one Commonwealth agency, separate OHS and compensation lists were received from New South Wales, Queensland, South Australia, and Victoria. Combined OHS and compensation lists were provided by the Northern Territory and Tasmania. Western Australia provided a detailed OHS list and a limited compensation list through the OHS agency. The Australian Capital Territory was unable to supply any OHS or compensation information. Comcare Australia provided data on relevant deaths of Commonwealth employees covered by the Comcare Australia scheme during the relevant period. All lists included the name of the individuals, except for the compensation list supplied by Western Australia (in which no records had names) and the Queensland OHS list (in which most records had names). Of other known small compensation bodies that covered some workers during the study period, access to relevant information was either not available and/or not requested.

\section{Approach to matching}

These agencies and the coroners' files do not share a common unique identifier for the same person. Therefore, unit record data were manually matched by name with the work related cases identified using information obtained from the coroners' files. Where names were not available from unit record data, records were matched with the coroners' data using whatever information was available from the list supplied (for example, date and description of incident for the Queensland OHS list). Where names were not available, matches were only accepted where the corresponding information made the match almost certain. Duplicate records and records of 
Table 2 Coverage (percent') of deaths by OHS and compensation agencies for each study category; Australia, 1989 to 1992 *

\begin{tabular}{|c|c|c|c|c|c|c|c|c|c|}
\hline Work category & $\mathrm{OHS}^{2} \%$ & Compo $\%$ & Both $4 \%$ & Comb $\%$ & None $^{6} \%$ & Number ${ }^{7}$ & $\underset{\%}{\text { OHS total }}{ }^{8}$ & $\underset{\%}{\text { Comp total }}{ }^{9}$ & $\begin{array}{l}\text { OHS and } \\
\text { Comp total } \\
\%\end{array}$ \\
\hline Workplace & 13.6 & 19.3 & 28.3 & 5.3 & 33.4 & 1107 & 47.2 & 52.9 & 66.6 \\
\hline Work-road & 0.8 & 57.3 & 5.7 & 1.8 & 34.3 & 487 & 8.4 & 64.9 & 65.7 \\
\hline All working & 9.7 & 30.9 & 21.4 & 4.3 & 33.7 & 1594 & 35.4 & 56.6 & 66.3 \\
\hline Commuting & - & 62.0 & 0.4 & 3.0 & 34.7 & 571 & 3.3 & 65.3 & 65.3 \\
\hline Working and commuting & 7.2 & 39.1 & 15.8 & 3.9 & 34.0 & 2165 & 26.9 & 58.9 & 66.0 \\
\hline Bystander (workplace) & 7.7 & 0.3 & - & - & 92.0 & 275 & 7.7 & 0.3 & 8.0 \\
\hline Bystander (road) & - & - & - & - & 100.0 & 434 & - & - & - \\
\hline All bystanders & 3.1 & 0.1 & - & - & 96.7 & 709 & 3.1 & 0.1 & 3.3 \\
\hline Volunteers & - & 11.8 & 11.8 & - & 76.5 & 17 & 11.8 & 23.5 & 23.5 \\
\hline Students & 2.8 & - & - & - & 97.2 & 36 & 2.8 & - & 2.8 \\
\hline Home duties & 6.0 & - & - & - & 94.0 & 266 & 6.0 & - & 6.0 \\
\hline Other on-farm & - & - & - & - & 100.0 & 39 & - & - & - \\
\hline \multicolumn{10}{|c|}{$\begin{array}{l}\text { *Excluding the Australian Capital Territory and Western Australia. This } \\
\text { study. }{ }^{12} \\
\text { 1: Percentages are based on the total number in each study category. } \\
\text { 2: On OHS list only. } \\
\text { 3: On compensation list only. } \\
\text { 4: On both OHS and compensation lists. } \\
\text { 5: On combined OHS/compensation list (NT and TAS). } \\
\text { 6: Not on any list. } \\
\text { 7: Number in study category. } \\
\text { 8: Total on any OHS list (including combined). } \\
\text { 9: Total on any compensation list (including combined). } \\
\text { 10: Total on any OHS, compensation or combined list. }\end{array}$} \\
\hline
\end{tabular}

compensation claims that were later denied by the relevant agency were excluded.

There were many instances where a record appeared on one of the agency lists but the person had not initially been included as a case using the coroners' information. All coroners' files relevant to these deaths were reviewed and, where necessary and possible, further information about the deaths was sought from other sources such as the relevant Registry of Births, Deaths, and Marriages. The most common reason for discrepancy arose because the person had not died from a non-suicide external cause death during the study period (and so did not meet the study definitions of a case and usually did not have a coroners' file). In these instances, one or more of the following applied: the person had died of a natural cause; had committed suicide; had died outside the study period; or had not died at all. These records were excluded from the comparison. Most of the other discrepancies arose when the person had died from a non-suicidal external cause but had not initially been included as a case using the coroners' information, either because the coroners' file contained insufficient information to appropriately classify the death as work related (accounting for the vast majority of these discrepancies), or because the relevant information had been missed or misinterpreted by the research officer who had consequently misclassified the death. All these persons were subsequently included as cases. Excluding Western Australia, matches were found for $99.3 \%$ of the entries on compensation lists and all entries on the OHS lists (table 1).

All cases included in the study were checked against the information supplied by the OHS and compensation agencies to determine whether the death was identified by one or more of the OHS, compensation, or combined agencies (from Tasmania and the Northern Territory). The data presented in this paper show the number and proportion of deaths identified only from the list of an OHS agency, only from the list of a compensation agency, from lists of both types of agencies, from the list of a combined agency, or which were not identified on any of the lists. Analysis describing total OHS agency and total compensation agency list coverage includes the combined lists from the Northern Territory and Tasmania, because the lists from these jurisdictions could not be separated into OHS matters and compensation matters. The analyses included separate stratification by case classification, industry, occupation, mechanism, and employment status. Data were analysed using the SAS system, version $8 .{ }^{13}$

Data from Western Australia were excluded from this analysis because of concern regarding the accuracy of the compensation data, as well as the fact that the lack of names made matching more difficult. No data were available from the Australian Capital Territory. However, coverage by Western Australian agencies for incidents that occurred elsewhere is included (there were two such cases with the Western Australian compensation agency). Also, compensation data were not available from some self insuring sectors, most notably in telecommunications and in the defence forces. Therefore, compensation information for the communication and defence force sectors should be interpreted with caution. However, since OHS authorities covered these industries, and the names of a small number of persons from the industries were on the compensation lists, the industries have been included in the relevant tables presented in this paper.

\section{RESULTS}

\section{Overall coverage}

This section primarily considers aggregate national results, but the main patterns were similar in all jurisdictions. The overall percentage of working deaths (workplace and workroad) covered by at least one of the agencies was $66 \%$. Conversely, $34 \%$ of working deaths were not covered by any agency. Only $35 \%$ of working deaths were covered by an OHS or combined agency, while $57 \%$ were covered by a compensation or combined agency. The OHS agencies had minimal coverage of work-road and commuting deaths, whereas the compensation system covered these deaths better than the workplace category. Looking at all work related deaths of workers (including commuting) the picture was much the same, with coverage by at least one agency of $66 \%$. 
Table 3 Coverage (percent') of deaths by OHS and compensation agencies by industry; Australia, 1989 to 1992 *

\begin{tabular}{|c|c|c|c|c|c|}
\hline Industry & Number ${ }^{2}$ & OHS total ${ }^{3} \%$ & Comp total ${ }^{4} \%$ & $\begin{array}{l}\text { OHS and Comp } \\
\text { total }^{5} \%\end{array}$ & None $^{6} \%$ \\
\hline Agriculture & 308 & 37.7 & 26.6 & 49.7 & 50.3 \\
\hline Forestry and logging & 40 & 62.5 & 57.5 & 70.0 & 30.0 \\
\hline Fishing and hunting & 47 & 6.4 & 17.0 & 19.1 & 80.9 \\
\hline Mining & 90 & 13.3 & 74.4 & 75.6 & 24.4 \\
\hline Manufacturing & 129 & 66.7 & 85.3 & 89.1 & 10.9 \\
\hline Electricity, gas, and water & 23 & 73.9 & 91.3 & 95.6 & 4.4 \\
\hline Construction & 219 & 64.8 & 70.8 & 87.2 & 12.8 \\
\hline Wholesale and retail trades & 107 & 38.3 & 59.8 & 69.2 & 30.8 \\
\hline Transport and storage & 332 & 19.3 & 69.3 & 71.7 & 28.3 \\
\hline Communication 7 & 12 & 8.3 & 25.0 & 33.3 & 66.7 \\
\hline Finance, property, and business services & 42 & 31.0 & 61.9 & 69.0 & 31.0 \\
\hline Public administration & 39 & 23.1 & 71.8 & 71.8 & 28.2 \\
\hline Defence $^{7}$ & 49 & 2.0 & 4.1 & 6.1 & 93.9 \\
\hline Community services & 65 & 23.1 & 56.9 & 64.6 & 35.4 \\
\hline Recreation, personal, and other services & 83 & 19.3 & 50.6 & 56.6 & 43.4 \\
\hline Not known & 9 & 33.3 & 44.4 & 66.7 & 33.3 \\
\hline Total & 1594 & 35.4 & 56.6 & 66.3 & 33.7 \\
\hline
\end{tabular}

*Excluding the Australian Capital Territory and Western Australia. This table includes all relevant cases included in the overall work related fatalities study. ${ }^{12}$

1: Percentages are based on the total number in each study category.

2: Number in industry category.

3: Total on any $\mathrm{OHS}$ list (including combined).

4: Total on any compensation list (including combined).

5: Total on any OHS, compensation or combined list.

6: Not on any list.

7: Most compensation information not available for this industry.

Almost one quarter of volunteers were covered by at least one of the agency types (most of these volunteers being volunteer firefighters). There was minimal coverage of any of the other study categories by any of the agencies. This low coverage is not surprising for the volunteer, student, home duties, and other on-farm deaths, although, interestingly, there was at least some coverage of the first three of these categories. However, the poor coverage of bystander deaths, whether in the workplace $(8 \%)$ or on the road $(0 \%)$, was clear (table 2).

The remaining results consider only working deaths (workplace and work-road).

\section{Industry}

There was considerable variation in overall coverage between industries, with electricity, gas, and water (96\%) and manufacturing (89\%) covered well, but defence (6\%), fishing (19\%), communication (33\%), and agriculture (50\%) covered relatively poorly. The OHS agencies' coverage ranged from $2 \%$ (defence) to $74 \%$ (electricity, gas, and water). The coverage was less than $20 \%$ of deaths for six of the 16 industry groups (notably fishing, mining, communication, and defence) and less than $40 \%$ of deaths for 11 industries. The compensation agencies' coverage varied from $4 \%$ in defence to $91 \%$ for electricity, gas, and water. Industries not well covered by the compensation agencies included fishing (17\%) and agriculture (27\%) (table 3).

\section{Occupation}

Overall coverage of occupation groups was best for tradespersons (83\%) and worst for managers and administrators (44\%). Apart from tradespersons $(63 \%)$ and labourers and related workers (46\%), the OHS agencies covered a third or less of the deaths in each occupation group. In contrast, coverage by compensation agencies was above $50 \%$ for all occupation groups except managers and administrators (22\%).

\section{Mechanism of incident}

Coverage of deaths varied considerably depending on the mechanism involved. Deaths covered reasonably well included those resulting from incidents involving slides/cave-ins
( $100 \%)$, being hit by moving objects ( $81 \%)$, rollovers of mobile mechanical equipment (76\%), contact with electricity $(76 \%)$, and falls $(75 \%)$. There was much lower coverage of deaths arising from incidents involving drowning $(26 \%)$, weapons $(35 \%)$, hitting objects $(50 \%)$, and contact with chemicals or other substances $(52 \%)$. Coverage patterns were similar for OHS and compensation agencies, except that coverage was particularly low in the OHS system for deaths arising from vehicle crashes $(8 \%)$, incidents involving weapons $(8 \%)$, and drowning (11\%) (table 4).

\section{Employment status}

The coverage by OHS agencies was similar regardless of the employment status of the deceased worker (employee $=38 \%$; self employed $=36 \%$; unpaid family helper $=24 \%$ ). In contrast, the coverage by compensation agencies was considerably higher for employees (73\%) than for self employed persons $(20 \%)$, and minimal for unpaid family helpers.

\section{DISCUSSION}

Problems with coverage of work related fatalities by OHS and workers' compensation agencies have important implications for the OHS community. In Australia, the compensation system currently provides the only regular, national OHS data on work related fatalities, and the OHS agencies the only detailed data on the circumstances surrounding these fatal incidents. Similarly, in many other countries, the compensation and OHS agencies' information is used to develop and monitor prevention initiatives. In an ideal world, the OHS agencies should investigate all work related deaths. However, this study implies an overall coverage of less than $40 \%$ of traumatic deaths of workers. Similar results have been found in the United States $(32 \%)^{6}$ and New Zealand $(40 \%)$, ${ }^{2}$ although the inclusion criteria were not exactly the same. Much higher coverage was documented in metropolitan Cape Town, in South Africa (72\%). ${ }^{4}$ This relatively low coverage is of particular concern because it is investigation by the OHS agencies that should provide the detailed information necessary to target prevention activity appropriately. The OHS authorities are the main source of effort in terms of OHS prevention and enforcement activity. Therefore, if it is assumed that this 
Table 4 Coverage (percent') of deaths by OHS and compensation agencies by mechanism; Australia, 1989 to $1992^{*}$

\begin{tabular}{|c|c|c|c|c|c|}
\hline Mechanism & Number $^{2}$ & OHS total ${ }^{3} \%$ & Comp total ${ }^{4} \%$ & $\begin{array}{l}\text { OHS and Comp } \\
\text { total }^{5} \%\end{array}$ & None ${ }^{6} \%$ \\
\hline Slide/cave in & 14 & 42.9 & 78.6 & 100.0 & - \\
\hline Being hit by moving objects & 443 & 61.0 & 63.2 & 80.6 & 19.4 \\
\hline Rollover & 63 & 61.9 & 41.3 & 76.2 & 23.8 \\
\hline Contact with electricity & 108 & 66.7 & 59.3 & 75.9 & 24.1 \\
\hline Falls & 157 & 55.4 & 63.1 & 74.5 & 25.5 \\
\hline Explosion & 17 & 52.9 & 64.7 & 70.6 & 29.4 \\
\hline Vehicle crash & 587 & 7.8 & 59.5 & 60.1 & 39.9 \\
\hline Contact with heat or cold & 16 & 37.5 & 43.8 & 56.2 & 43.8 \\
\hline Chemicals, other substances & 23 & 47.8 & 43.5 & 52.2 & 47.8 \\
\hline Hitting objects & 14 & 21.4 & 42.9 & 50.0 & 50.0 \\
\hline Weapons & 62 & 8.1 & 32.3 & 35.5 & 64.5 \\
\hline Drowning & 84 & 10.7 & 21.4 & 26.2 & 73.8 \\
\hline Other and unknown & 6 & 16.7 & 16.7 & 33.3 & 66.7 \\
\hline Total & 1594 & 35.4 & 56.6 & 66.3 & 33.7 \\
\hline
\end{tabular}

*Excluding the Australian Capital Territory and Western Australia. This table includes all relevant cases included in the overall work related fatalities study. ${ }^{12}$

1: Percentages are based on the total number in each study category.

2: Number in mechanism category.

3: Total on any $\mathrm{OHS}$ list (including combined).

4: Total on any compensation list (including combined).

5: Total on any OHS, compensation or combined list.

6: Not on any list.

activity is useful in improving the level of OHS, lack of awareness by the authorities of the details of a large proportion of incidents in particular areas is likely to have a negative impact, because priorities may be wrongly assessed.

The results presented here reveal that particular industries, occupations, and mechanisms are not well covered by OHS agencies. Low coverage of the defence force incidents is not surprising, since the military covers this area itself. Although this may have practical and administrative advantages for the military, there is the potential to miss the opportunity for constructive OHS responses to fatal incidents if an OHS authority is not involved in the investigation and in consideration of prevention activities. A similar situation exists with the fishing and mining industries, with some of the low coverage by the OHS agencies probably being related to involvement by a marine safety authority or mining inspectorate respectively. As with the defence forces, these non-OHS agency authorities have specialist knowledge and skills which are clearly of importance in the investigation procedure. However, a strong case should be made for having the additional involvement of a non-sectoral agency which can examine incidents from a broader perspective. This has the advantages of them not being as open to influence by accepted industry norms, as well as gaining information that might be relevant to preventive activities in other industry sectors. In addition, it is of concern that the two industries with the highest number of deaths (agriculture and transport) have low coverage by OHS agencies (38\% and $19 \%$ respectively). Low coverage of rural and transport industries has also been identified in New Zealand, ${ }^{2}$ South Africa, ${ }^{45}$ and the United States. ${ }^{6}$ The potential for appropriate prevention activity, or prosecution under OHS legislation when this is warranted, is thus being diminished in two major industry sectors with high fatal injury risk.

There are also some important classes of incidents which are largely neglected by the OHS agencies, with vehicle crashes $(8 \%)$ and incidents involving weapons, mainly assaults (8\%), being the two most stark examples. Presumably the investigation in these areas is left to the police, who then take whatever action they deem appropriate. However, the police are primarily interested in determining who was at fault in an incident and in identifying any breaches of the law. Any consideration of the possible contribution of OHS factors is therefore likely to assume a low profile. Factors such as shift rosters, equipment maintenance, hours of work, security, and lighting may be relevant to incidents in one or both of these areas. Yet, if the OHS agencies are not involved in the investigation of such incidents, such factors may not receive due attention.

There was minimal coverage of workplace bystander deaths by OHS agencies (and compensation agencies) and no coverage at all of road bystander deaths. This means that an important area where work is having an adverse (and presumably preventable) effect on the community is not being recognised and is consequently having little specific effort directed at it by the OHS community.

Compensation data, available from State and Territory agencies and the National Data Set, ${ }^{14}$ remain the primary source of OHS information in Australia, even though the system is designed to only cover employees. With the compensation agencies covering 57\% of deaths of working persons (or $59 \%$ of deaths if commuting is included), this means that about $40 \%$ of the traumatic work related deaths of workers (and virtually all bystander deaths) are not being reflected in official routine statistics. As for OHS agency coverage, the coverage by compensation agencies in Australia was similar to that found elsewhere- $57 \%$ in the United States ${ }^{6}$ and $63 \%$ in New Zealand. ${ }^{2}$ Published compensation information therefore significantly underestimates the magnitude of work related traumatic death of workers and provides virtually no information on the deaths of non-working persons killed as a result of someone else's work, whether in a workplace or on the road.

The effect of employment status was much as expected. The coverage of working deaths by OHS agencies did not appear to be related to whether the person was an employee or self employed, except that coverage was lower for unpaid family helpers and very low for persons whose employment status was in the "other and unknown" category. The lower coverage of unpaid family helpers (and persons with unknown employment status) probably arises from the fact that many of them were in the agriculture industry, where coverage was lower for all workers, or were involved in incidents whose mechanism type was generally poorly covered by OHS agencies.

The compensation agencies had reasonable (but nowhere near complete) coverage of employees, but not of persons deemed to be self employed for practical purposes. In addition, some persons who are for practical purposes self employed 
have arrangements that make them legally employees of their own company. When this legal definition of employment status was used, the difference in compensation coverage between employees (74\%) and self employed persons $(2 \%)$ was even starker.

\section{Data limitations}

There are some limitations to the analyses presented here. These arise from the absence of data from some small compensation areas, from errors or uncertainties in the data supplied by the jurisdictions and from uncertainty about the industries and employment status of workers covered by the compensation and OHS agencies.

Firstly, some small compensation bodies did not contribute data to the study. This is likely to have biased the results for the communications, defence, and merchant shipping (in transport) industries, but not to have importantly affected the results, or the conclusions made from them. For example, if persons employed in telecommunications, merchant shipping, and the defence forces are excluded, the percentage of deaths not covered by any OHS or compensation agency becomes $31 \%$, compared with the $34 \%$ found in the main analyses that included these groups.

Some of the jurisdictions were unable to be certain that all claims that appeared on their list had been accepted and/or were for fatal incidents. Many of the lists also clearly included natural cause deaths. Non-accepted claims were excluded for this comparison where this was indicated on the list, but for all other records on the list it had to be assumed that the claim had been accepted. This approach may have resulted in a slight overestimation of the extent of coverage by the compensation system. Similarly, records that could not be found on the Australian Bureau of Statistics' Deaths Data List or in the coroners' system were not excluded unless there was reliable information that the record related to an incident which involved a natural cause death, suicide, did not result in death, or which occurred outside the study period. This conservative approach is likely to slightly overestimate the percentage of missing data. Since only $0.7 \%$ of compensation agency records could not be accounted for in some definitive way, this problem is unlikely to have been of any importance.

Finally, it should be noted that these data refer to the period 1989 to 1992 and so reflect the coverage of the OHS and compensation agencies during that period. There have been some changes in these systems since then that may modify the conclusions made on the basis of these findings. However, it is unlikely that these changes would have substantially improved the coverage of either the OHS or compensation systems. In fact, legislative changes to remove commuting deaths from coverage by compensation systems in some jurisdictions will have significantly decreased the coverage of these deaths.

With much of the limitation in coverage arising from legislation (particularly for compensation agencies) or convention (particularly for OHS agencies), improvements will be difficult to achieve and always subject to change through processes not connected to levels of safety for workers. Therefore, when using data from official sources, the limitations in coverage identified in this paper need to be taken into account. The only comprehensive, robust, and reliable source of data on work related fatalities in Australia is the coroners' system. To date, coroners' information has not been used routinely, because most of the information is not stored electronically and there is no reliable indicator of work relatedness, either in the coroners' system or on death certificates. This has meant that information on work related deaths could only be obtained through resource intensive specific studies. ${ }^{12}{ }^{15}$ Fortunately, a National Coroners Information System (NCIS) is currently being established by the Australian Coroners' Society and the State and Territory governments. The NCIS is a national, computerised data storage, coding, and retrieval system designed to allow prompt access to coroners' information, and it is likely that the system will be the basis of future surveillance of work related traumatic death at both State and Territory and national level.

\section{ACKNOWLEDGEMENTS}

The authors wish to thank the many individuals and government agencies who provided assistance in the design, planning, and conduct of the study. They also wish to thank Ms Eui-Soo Choi and Ms Amelia Howland, who contributed to aspects of the design, conduct, and analysis of the study. The views in this publication are those of the authors and do not necessarily reflect those of the National Occupational Health and Safety Commission.

\section{Authors' affiliations}

T Driscoll, Centre for Occupational and Environmental Health, University of Sydney, Member; former Head, Epidemiology Unit, National

Occupational Health and Safety Commission (NOHSC)

R Mitchell, Injury Prevention Policy Unit, NSW Department of Health, Senior Policy Analyst; former Project Officer at NOHSC

J Mandryk, National Prescribing Service, Program Evaluation Officer; former Senior Research Scientist at NOHSC

S Healey, LIPID Coordinating Centre, University of Sydney, Data Manager; former Project Officer at NOHSC

L Hendrie, Health Communication Network, Data Analysts, former Project Officer at NOHSC

B Hull, National Centre for Immunisation Research and Surveillance, Epidemiologist; former Project Officer at NOHSC

\section{REFERENCES}

1 Herrington TN, Morse LH. Occupational injuries. Evaluation, management, and prevention. St Louis: Mosby Year Book Inc., 1995.

2 Langley J, Feyer A, Wright C, et al. Work-related fatal injuries in New Zealand: can a reliable electronic work-related fatality register be established? Journal of Occupational Health and Safety-Australia and New Zealand 2000;16:145-53.

3 Leigh JP, Markowitz S, Fahs M, et al. Costs of occupational injuries and illnesses. Ann Arbor: University of Michigan Press, 2000

4 Lerer LB, Myers JE. Application of two secondary documentary sources to identify the underreporting of fatal occupational injuries in Cape Town, South Africa. Am J Ind Med 1994;26:521-7.

5 Schierhout GH, Midgley A, Myers JE. Occupational fatality under-reporting in rural areas of the Western Cape Province, South Africa. Safety Science 1997;25:113-22.

6 Stout N, Bell C. Effectiveness of source documents for identifying fatal occupational injuries: a synthesis of studies. Am J Public Health $1991 ; 81: 725-8$.

7 Takala J. Global estimates of fatal occupational accidents. Epidemiology 1999; 10:640-6.

8 Australian Bureau of Statistics (ABS). Work-related injuries and illnesses, New South Wales, October 1993. Catalogue No. 6301.1. Canberra: AGPS, 1994.

9 Driscoll T, Hanson M. Work-related injuries in trade apprentices. Aust N Z J Public Health 1997;21:767-71.

10 Fingar AR, Hopkins RS, Nelson M. Work-related injuries in Athens County 1982 to 1986. A comparison of emergency department and workers' compensation data. J Occup Med 1992;34:779-87.

11 Murphy PL, Sorock GS, Courtney TK, et al. Injury and illness in the American workplace: a comparison of data sources. Am J Ind Med 1996;30:130-41

12 Driscoll T, Mitchell R, Mandryk J, et al. Work-related fatalities in Australia, 1989 to 1992: an overview. Journal of Occupational Health and Safety-Australia and New Zealand 2001;17:45-66.

13 SAS Institute (SAS). SAS system, version 8.0. SAS Institute: Cary, NC, 1999.

14 National Occupational Health and Safety Commission. National dataset for compensation-based statistics. Canberra: AGPS, 1987

15 Harrison J, Frommer $M$, Ruck E, et al. Deaths as a result of work-related injury in Australia. Med J Aust 1989;150:118-25. 